\title{
educação

\section{Conhecer contextos, conhecer profissionais: Contributo para explorar o desenvolvimento de competências interculturais em contextos educativos}

\author{
Daniela Filipa Santos Silva \& Sofia Marques da \\ Silva ${ }^{\text {II }}$
}

Universidade do Porto, Portugal

\begin{abstract}
$\mathrm{O}$ aumento de mobilidades e de movimentos migratórios na sociedade contemporânea europeia tem reflexo nos mais diversos contextos sociais, trazendo desafios particulares ao campo educativo. Neste alinhamento, as questões da diversidade cultural tornam-se audíveis não apenas pela emergência de situações mediatizadas, mas também porque nos relembram "velhas" diversidades, por vezes esquecidas. Este artigo procura contribuir para uma discussão em torno de preocupações que, sendo também de natureza global, se estendem a contextos educativos locais, onde diversidades culturais se vivem e produzem envolvendo diferentes figuras. $\mathrm{O}$ contributo decorre de um estudo qualitativo que procurou dar conta de competências valorizadas, apropriadas e mobilizadas por profissionais em contextos educativos formais, não formais e informais, no trabalho com diversidades étnicas, especificamente com jovens descendentes de imigrantes e de minorias étnicas. As entrevistas semiestruturadas e grupos de discussão focalizada possibilitaram conhecer um conjunto de competências profissionais que se organizaram em três dimensões: uma dimensão relacional, uma dimensão prática e uma dimensão de integração cultural e social.
\end{abstract}

Palavras-chave: Educação inter/multicultural; Competências profissionais; Diversidade cultural

\section{INTRODUÇ ÃO}

As crescentes mobilidades e movimentos migratórios nas sociedades contemporâneas, a europeia em particular, tornam mais audíveis as questões da diversidade cultural e étnica, trazendo à superfície discursos em torno de constrangimentos, inseguranças e medos, mas também discursos sobre potencialidades, cidadania e inclusão; neste enquadramento, a construção de uma cidadania ativa e a inclusão plena são vistas como dimensões essenciais de desenvolvimento pessoal de todas as comunidades. A partir dos anos 1960, com os movimentos contraculturais, tem-se assistido a uma "rebelião das diferenças" (Magalhães \& Stoer, 2005, p. 131) que vem questionando o conceito de cidadania, que, nas definições da sua 
génese, é associado à pertença conformada e à homogeneidade (Araujo, 2009). A pertinência de discutir o que está em causa, e que decorre da intensidade de movimentos migratórios, ganha ainda maior relevância dada a situação atual em diferentes países europeus confrontados com a chegada de vagas de pessoas refugiadas. Estas vagas significam novos desafios para diferentes contextos sociais e políticos e, particularmente, para os contextos educativos e com um necessário impacto na formação de profissionais. Contudo, "velhas" diversidades, presentes há muito tempo nas sociedades europeias e no contexto português, têm sido mais esquecidas, nomeadamente em termos educativos e no mundo do trabalho. Os ciganos, em Portugal há mais de cinco séculos, "permanecem ainda como um grupo não (re)conhecido pela sociedade portuguesa maioritária" (Mendes, Magano, \& Candeias, 2014, p. 12). A entrada de novas comunidades nas regiões e sociedades europeias traz novos desafios e ações que poderão ser potenciados e transferidos para a integração das comunidades que continuam estrutural e tradicionalmente nas periferias da sociedade portuguesa e, em particular, nas margens dos contextos educativos.

A escola pública é o espaço educativo que, pela sua natureza política e pela função social de cidadania e democracia (Silva, 2016), tem por princípio o acolhimento de "uma enorme diversidade de jovens em termos sociais, culturais e identitários" (Silva, 2008, p. 142), tendo um papel crucial no desenvolvimento deste trabalho de integração e inclusão das comunidades. No entanto, comunidades como a cigana continuam a apresentar uma elevada percentagem de abandono e absentismo escolares (Casa-Nova, 2006).

É a partir desta discussão, da sua importância no campo educativo e da relevância de contribuir para a integração das comunidades imigrantes em Portugal, que surge uma pesquisa qualitativa, no âmbito do Mestrado em Ciências da Educação, com o objetivo de dar conta de competências valorizadas, apropriadas e mobilizadas por diferentes profissionais em contextos educativos formais, não formais e informais no trabalho com a diversidade étnica e cultural, especificamente com jovens descendentes de imigrantes e de minorias étnicas.

O artigo apresenta, primeiramente, uma discussão teórica em torno das problemáticas da diversidade étnica e cultural e, de seguida, uma breve referência teórica ao desenvolvimento do conceito de competências interculturais. Posteriormente, apresentam-se os resultados da pesquisa bem como a sua discussão e, finalmente, uma breve conclusão.

\section{Diversidade: Conceitos E QUADROS TEÓRICOS DE LEITURA}

Tendo em consideração que "[as] democracias são hoje desafiadas, em maior ou menor grau e de forma mais ou menos radical, pela interpelação ou simplesmente existência no seu seio de vários grupos culturalmente diferentes" (Nata, 2007, p. 23), as questões da diversidade e de relação com o "outro" têm sido alvo de atenção no campo científico das Ciências da Educação, nomeadamente no que diz respeito às interações e relações que se estabelecem no contexto escolar, um espaço ainda de tensões entre identidades e diferenças (Silva, 2008) pela estranheza encontrada entre as identidades juvenis e o projeto da Escola.

Apoiando-nos na ideia de que o estatuto do 'outro' em educação não é externo ao ato educativo nem à relação interpessoal em que esse ato se apoia (Magalhães \& Stoer, 2011), a educação e os contextos educativos assumem particular importância na promoção da integração de imigrantes vindos de vários pontos do globo. Trabalhos de Leite (2003, 2005), por exemplo, contribuíram para a discussão 
da multiculturalidade no espaço escolar, das implicações curriculares e dos desafios da prática docente perante a multiculturalidade, apontando para a consciência de que “educadores/as e professores/as devem agir no sentido de implementarem reformas curriculares multiculturais que permitam não só a compreensão das culturas em presença mas também a aquisição de uma competência geradora de uma emancipação cultural" (Leite, 2005 , p. 10). A perspetiva de uma educação multicultural deve apontar, como refere Banks já em 1995, para a reforma da escola e de outras instituições educativas de modo a que estudantes de diferentes etnias e classes sociais possam experienciar uma igualdade educativa.

A diversidade é "um termo frequentemente utilizado dentro da área da cidadania e educação cívica na Europa [e] a sua imprecisa conceptualização espelha os atuais desafios societais na Europa" (Zimenkova, 2011, p. 23). Importa aqui clarificar o conceito de 'diversidade' uma vez que este se inscreve dentro de uma heterogeneidade de campos e práticas (Cortesão, Costa, Rodrigues, \& Trindade, 2002). O significado inicial era referente a grupos minoritários compostos por elementos de diversas etnias. No entanto, com a crescente multiplicidade e uma consequente heterogeneidade de comunidades, "[a] diversidade de alunos que passou a frequentar a escola provocou um redimensionar do próprio conceito de diferença”" (Tavares \& Sanches, 2013, p. 308), alargado às questões das necessidades educativas especiais, da multiculturalidade, da etnia, da nacionalidade, da classe social e das diferenças de género. Neste trabalho, e tendo em conta que nos referimos a comunidades de diversidade étnica, cultural e migrante, o conceito de diversidade refere-se à coexistência de grupos dominantes e grupos minoritários (em termos de poder) constituídos por diferentes etnias cobrindo segundas e subsequentes gerações de imigrantes (Cortesão et al., 2002). Consideramos também o modo como as questões de classe, principalmente, atravessam as comunidades e o modo como as diferenças dialogam entre si.

Uma questão relevante quando se procura compreender o trabalho de profissionais em contextos de diversidade diz respeito à própria diversidade étnica e cultural do grupo de profissionais docentes em contexto escolar. $\mathrm{Ou}$ seja, a escassa existência, em Portugal, de docentes com características culturais e étnicas diferentes da portuguesa poderá revelar-se como um obstáculo neste trabalho educativo específico. De facto, se considerarmos a população docente, esta permanece relativamente homogénea (OECD Report, 2010), enquanto a heterogeneidade na sala de aula vai aumentando. Não se defendendo aqui que docentes com background migrante ou de diferentes etnias devam ficar alocados a turmas com essas características, uma reflexão sobre a baixa percentagem de docentes com essas características, pelo menos em Portugal, é necessária. Assim, pode-se questionar a pouca atratividade da profissão docente para pessoas dessas comunidades: o insucesso escolar destes grupos étnico-culturais tem, necessariamente, consequências no acesso ao ensino superior. Pode-se também discutir as vantagens de termos um grupo de docentes cuja diversidade possibilite um maior reconhecimento de diferentes culturas e melhor compreensão das mesmas, podendo estes/as funcionar como mediadores/as entre culturas.

\section{O CONCEITO DE COMPETENCIAS}

\section{N T E R C U L T U R A I S}

Durante os anos 1990, a introdução do conceito de competência no campo educativo foi feita através da relação com a formação de professores/ as e influenciou reformas educativas em diversos países da União Europeia (Council of Europe, 2009). Neste sentido, e aproximando-nos de 
uma definição mais esclarecedora de acordo com os objetivos deste trabalho, o conceito de competência assume-se como uma combinação de conhecimento, 'skills', entendimentos, valores e atitudes aplicadas à ação num determinado contexto, implicando sempre um sentido de agência, ação e valor (Huber \& Reynolds, 2014; Siewiorek, Vivitsou, \& von Reis Saari, 2013). Adotamos este conceito, mesmo sabendo que pode ser controverso na sua utilização, pois consideramos que remete para uma série de práticas e aptidões que profissionais utilizam diariamente no exercício das suas atividades, assumindo a "articulação de três registros de variáveis: saberes, esquemas de acção, um reportório de condutas e de rotinas disponíveis" (Perrenoud, Paquay, Altet, \& Charlier, 2001, p. $90)^{1}$, tomando a prática reflexiva (e não só as aptidões naturais e visíveis na prática) como uma importante dimensão da competência inter/ multicultural.

Nas últimas décadas, foi dada uma grande importância ao constructo de "key competence"2, inicialmente para dar conta de comparações internacionais relacionadas com o sucesso escolar através de sistemas nacionais de referência (PISA, PIRLS, TIMSS, etc.) (Council of Europe, 2009). Enquanto o termo competência se refere a um processo de se tornar e estar qualificado, o conceito de "key competences" refere-se particularmente a competências específicas que podem ser utilizadas "to master a variety of situations and demands seen, as in this case, from a diversity perspective" (Council of Europe, 2009, p. 3). Neste sentido, assumimos a definição do conceito de competências incluindo o de "key competences", pois parece-nos o mais abrangente e diversificado para tratar o objeto que nos propomos estudar, pela multiplicidade de sujeitos e contextos em análise neste estudo, sendo necessário adotar uma conceção abrangente do conceito e compreender o modo como, no terreno, é apropriado e se traduz em práticas.

Estudos e relatórios (Huber \& Reynolds, 2014; UNESCO, 2013) têm vindo a desenvolver análises sobre competências interculturais. Considera-se, deste modo, que as competências interculturais requerem estar aberto/a, curioso/a e interessado/a nas comunidades que têm afiliações culturais distintas e a capacidade de compreender e interpretar as suas práticas, valores e discursos (Huber \& Reynolds, 2014). Os estudos acima referidos permitiram chegar a algumas competências-chave para o trabalho em contextos de diversidade: i) capacidade de reconhecer a importância da construção de relações de confiança; ii) competência "plurilinguística" - capacidade de conhecer diversas línguas e promover a manutenção das culturas de origem através do conhecimento das línguas maternas e do desenvolvimento das mesmas; iii) respeito, tolerância e empatia pelo 'outro' diferente; iv) valorização e compreensão da diversidade cultural; v) entender a diferença como uma oportunidade de aprendizagem e não como um obstáculo à mesma; vi) conhecimento das crenças, valores e práticas das diferentes culturas; vii) capacidade de se "descentralizar" de si próprio e considerar múltiplas perspectivas; viii) capacidade de adaptar os comportamentos a diferentes contextos e públicos (Huber \& Reynolds, 2014; Siewiorek et al., 2013).

Uma meta-análise de diferentes produções académicas realizada por Severiens, Wolff, e van Harpen (2013) aponta para a necessidade de dar atenção às questões da Língua, uma vez que muitas crianças utilizam em casa uma Língua

\footnotetext{
${ }^{1} \mathrm{O}$ trabalho de Perrenoud et al. (2001) sugere estas três variáveis em relação para a construção de uma competência no domínio profissional de docentes.

${ }^{2}$ Conceito determinante na sequência deste trabalho, uma vez que procuramos "competências-chave" no trabalho com jovens descendentes de imigrantes e pertencentes a minorias étnicas.
} 
diferente da utilizada nas escolas (Severiens et al., 2013), e à prática pedagógica conhecedora das diferenças culturais com que o/a profissional trabalha, bem como para a importância de estes profissionais desenvolverem competências no âmbito do conhecimento das histórias de vida dos/as seus/suas alunos/as, reconhecendo as especificidades dos/as mesmos/as; tratase de importantes competências no trabalho com minorias étnicas e migrantes (Leite, 2005; Pereira, 2004). Os processos de interação social mediados por questões de identidade têm igualmente influência na prática profissional com as diversidades. Falamos de estereótipos, expectativas de professores/as e profissionais e questões identitárias de nível étnico e cultural (Severiens et al., 2013) que necessitam de ser compreendidos para um trabalho de qualidade com a diversidade. As competências interculturais são adquiridas através de uma combinação de experiência, formação e reflexividade do/a próprio/a profissional (UNESCO, 2013).

O conceito de professor inter/multicultural ${ }^{3}$ (Stoer, 1994) permite também discutir a necessidade de aquisição de competências como: (i) o entendimento da diversidade como fonte de riqueza; ii) a promoção da rentabilização de saberes e de culturas, tendo em consideração a diversidade na sala de aula; iii) a reconceptualização do mapa da identidade cultural do/a professor/a para ultrapassar questões de etnocentrismo ${ }^{4}$ cultural; iv) a defesa da escola como parte da comunidade local; e v) o reconhecimento de diferenças culturais através do desenvolvimento de dispositivos pedagógicos ${ }^{5}$ com base da noção de cultura como prática social.

A discussão em torno desta problemática tornou-se crucial para a compreensão das questões interculturais em contextos educativos. É nesta senda que apresentamos, de seguida, a metodologia utilizada para responder ao objetivo deste trabalho.

\section{METODOLOGIA}

A pesquisa aqui apresentada coloca a sua preocupação na auscultação das vozes marginalizadas que ganham relevância num tempo em que as grandes narrativas estão falidas (Magalhães \& Stoer, 2005) e segue-se fugindo de um centralismo histórico, para um processo ideologicamente contraditório, rumo às narrativas locais e globais (Hall, 2003). Se procuramos ouvir as vozes e os múltiplos sentidos subjetivos dados ao social e aos fenómenos sociais, afirmamos a sua justificação dentro de um "paradigma qualitativo" (Silva, 2011, p. 51), no qual as suas metodologias propõem "a compreensão dos comportamentos a partir da perspectiva dos sujeitos da investigação" (Bogdan \& Biklen, 1994, p. 16).

Assente o objetivo e manifesta a necessidade de auscultação dos sujeitos, colocava-se a necessidade de procura de contextos que nos ajudassem a desconstruir e compreender a

\footnotetext{
${ }^{3} \mathrm{O}$ termo 'multicultural' "describes the culturally diverse nature of human society. It not only refers to elements of ethnic or national culture, but also includes linguistic, religious and socio-economic diversity" (UNESCO, 2006, p. 17). O termo 'intercultural' refere-se à "existence and equitable interaction of diverse cultures and the possibility of generating shared cultural expressions through dialogue and mutual respect” (UNESCO, 2006, p. 17).
}

${ }^{4}$ Etnocentrismo: "atitude que leva um indivíduo a apreender o outro ... segundo as normas e os valores do seu próprio grupo. Traduz-se... pela valorização de si próprio e pela depreciação do outro" (Echaudemaison, 2001, p. 149).

${ }^{5}$ Bernstein (1990) recorre a este conceito para analisar a estrutura da comunicação escolar. Segundo ele, o dispositivo pedagógico desenvolve-se em três contextos: i) o da produção/reprodução da cultura; ii) o da transmissão dessa cultura; iii) o da sua aquisição; e é regido pelas regras de distribuição (que distribui diferentes formas de consciência a diferentes grupos), de recontextualização (que regula a constituição de um discurso pedagógico específico) e de avaliação (que constitui a prática pedagógica e concentra em si todo o sistema). 
problemática. A aceção inicial foi a de procurar contextos educativos (formais, não-formais e informais) em que a diversidade étnica e cultural fosse significativa. Neste sentido, a escolha de contextos em que pudéssemos investigar partiu da variedade de etnias, culturas e nacionalidades que os mesmos nos pudessem oferecer.

Alguns dos projetos inseridos no Programa Escolhas foram opções, tanto pela proximidade e facilidade em entrar em contextos do Programa, como pelo objetivo e contextualização do mesmo:

O Escolhas é um programa governamental de âmbito nacional, criado em 2001, promovido pela Presidência do Conselho de Ministros e integrado no Alto Comissariado para as Migrações - ACM, IP, cuja missão é promover a inclusão social de crianças e jovens de contextos socioeconómicos vulneráveis, visando a igualdade de oportunidades e o reforço da coesão social. ${ }^{6}$

Neste sentido, foram selecionados três projetos do Programa: um na zona de Vila Nova de Gaia, outro no Grande Porto e um terceiro na Grande Lisboa. Pareceu-nos também pertinente a análise destas questões de investigação em contextos diferentes relativamente à zona geográfica, uma vez que as questões da diversidade são trabalhadas e encaradas de forma diferente de contexto para contexto e de área para área. Pretendíamos também ter contacto com contextos escolares que tivessem uma diversidade étnica e cultural significativa. A assunção inicial foi investigar em escolas da mesma área geográfica que a dos projetos do Programa Escolhas. No entanto, o contacto com o contexto escolar nem sempre é facilitado, pelo que recorremos a instituições escolares onde já tivéssemos contactos privilegiados. Assim, foram selecionadas duas escolas (que iremos referir como escola 1 e escola 2). Ambas situadas na zona oriental da cidade do Porto, estas escolas estão inseridas no programa TEIP (Territórios Educativos de Intervenção Prioritária) e apresentam uma diversidade étnica e cultural significativa, sendo que a maioria dos/ as estudantes provém de bairros sociais do Porto, havendo também uma percentagem significativa de estudantes de etnia cigana.

Após análise da literatura sobre o tema, foram construídos os guiões das entrevistas, que focaram diversos temas: Relação com a profissão; Formação de profissionais; Relação/ trabalho com jovens pertencentes a minorias étnicas e descendentes de migrantes; Dimensão de inclusão e culturas; Redes de apoio/trabalho em rede.

Foram realizadas 15 entrevistas com diferentes figuras profissionais (Quadro 1).

Foram ainda realizados três grupos de discussão focalizada (GDF) com jovens que participavam nos projetos do Programa Escolhas. Recorremos também a um grupo de discussão com profissionais de diversas áreas e com jovens, realizado no âmbito da Rede Sirius e Projeto $\mathrm{NAOS}^{7}$. Os grupos de discussão com jovens foram realizados nos contextos dos Programas Escolhas.

- GDF 1 - Programa Escolhas em Vila Nova de Gaia: seis jovens (dois do sexo feminino, quatro do sexo masculino); idades compreendidas entre os 11 e os 14

\footnotetext{
${ }^{6}$ Disponível em: http://www.programaescolhas.pt/

7 "The central topic of NAOS is professional capacity of teachers concerning dealing with diversity related to migration (in all its different forms). Professional capacity includes innovative forms of cooperation between educational professionals and other professionals dealing with children" (http://www.sirius-migrationeducation.org/naos/). Este grupo de discussão insere-se nas atividades deste projeto onde as investigadoras estiveram presentes como parte da organização da sessão e sobre o qual nos foi dada a devida autorização para podermos utilizar e analisar dados neste trabalho.
} 
QUA D RO 1 - Caraterização da amostra (Entrevistas)

\begin{tabular}{|c|c|c|c|}
\hline \multicolumn{4}{|c|}{ ENTREVISTAS } \\
\hline Sexo & Idade & Profissão & Formação inicial - Formação pós-graduada \\
\hline $\mathrm{F}$ & 83 & Professora Catedrática Jubilada na UP & Biologia - Doutoramento em Educação \\
\hline M & 45 & Professor/Diretor de Agrupamento de Escolas & Geografia \\
\hline M & 44 & Docente Escola Superior de Educação do Porto & $\begin{array}{l}\text { Literatura Espanhola - Doutoramento em } \\
\text { Ciências da Educação }\end{array}$ \\
\hline M & 26 & Dinamizador Comunitário Programa Escolhas & $12^{\circ}$ ano \\
\hline $\mathrm{F}$ & 30 & $\begin{array}{c}\text { Mediadora Socioeducativa em Contexto } \\
\text { Desportivo }^{8}\end{array}$ & Mestrado em Ciências da Educação \\
\hline $\mathrm{F}$ & 23 & Dinamizadora Comunitária Programa Escolhas & $12^{\circ}$ ano \\
\hline $\mathrm{F}$ & 23 & Animadora Sociocultural Programa Escolhas & Psicologia da Saúde \\
\hline M & $\mathrm{s} / \mathrm{i}$ & Professor/Diretor de Agrupamento de Escolas & $\begin{array}{l}\text { Geografia - Mestrado em Administração e } \\
\text { Gestão Escolar }\end{array}$ \\
\hline $\mathrm{F}$ & 40 & Coordenadora do Projeto Escolhas & Psicologia Clínica \\
\hline M & 32 & Dinamizador Comunitário Programa Escolhas & $12^{\circ}$ ano \\
\hline M & 22 & $\begin{array}{l}\text { Assistente Administrativo/Presidente Associação } \\
\text { Juvenil }\end{array}$ & $12^{\circ}$ ano \\
\hline M & 32 & Docente Escola Superior de Viana do Castelo & $\begin{array}{c}\text { Doutoramento em História/ Pós-Doutoramento em } \\
\text { Educação }\end{array}$ \\
\hline $\mathrm{F}$ & 34 & Psicóloga Escolar & Psicologia \\
\hline $\mathrm{F}$ & $s / \mathrm{i}$ & Representante ACM & $s / i$ \\
\hline $\mathrm{F}$ & $s / \mathrm{i}$ & Representante PAR & $s / i$ \\
\hline
\end{tabular}

anos; nacionalidades: portugueses/as, dois jovens com pais angolanos e iraquianos, um jovem português de uma das comunidades ciganas instaladas na região.

- GDF 2 - Programa Escolhas em Lisboa e Associação Juvenil (os jovens pertenciam a um projeto do Programa Escolhas e a uma Associação Juvenil): seis jovens (cinco do sexo feminino e um do sexo masculino); idades compreendidas entre os 12 e os 15 anos; nacionalidades: portuguesa, pais e avós africanos/as, angolana e brasileira.

- GDF 3 - Programa Escolhas no Porto: cinco jovens (quatro do sexo masculino, um do sexo feminino); idades compreendidas entre os 11 e os 16 anos; nacionalidades: portuguesa; três jovens de uma das comunidades ciganas instaladas na região.

- GDF 4 - Profissionais e jovens: uma docente da FPCEUP e membro da Rede Sirius; um docente da Universidade Autónoma de Barcelona e membro da Rede Sirius; uma representante da Rede Europeia Anti-Pobreza Portugal; a presidente da Associação Mais Brasil; uma representante da FNAJ (Federação Nacional de Associações Juvenis); duas estudantes de doutoramento em Ciências da Educação; um investigador do CIEE/FPCEUP; uma técnica do Programa Escolhas; uma

${ }^{8}$ A opção por um contexto desportivo tem em conta a diversidade étnica e migrante existente neste contexto particular, que recebe jogadores de futebol deslocados dos seus países para a prática desportiva. 
coordenadora de um dos projetos do Programa Escolhas; um jovem guineense presidente de uma Associação Juvenil de Lisboa; dois jovens cabo-verdianos e membros de uma Associação Juvenil de Lisboa; uma psicóloga; a presidente da Associação dos Imigrantes de Leste; e uma bolseira de investigação do CIIE/FPCEUP.

A escolha destes/as jovens justifica-se pelas condições dos contextos institucionais e, consequentemente, aqueles/as que estariam disponíveis no momento para poder conversar connosco, sendo que o fator ser descendente de imigrante ou pertencente a uma minoria étnica teria de estar assegurado, mesmo que não pudesse ser garantido em todos/as os/as participantes. Considera-se que a diversidade de sujeitos com que nos preocupamos em auscultar traz contributos necessários e extremamente diversificados, pela sua posição geográfica', institucional, etária e étnica, que em muito enriquecem a investigação, que se pretende que seja de caráter compreensivo e crítico.

Realizados e transcritos as entrevistas e os grupos de discussão, submeteu-se o material empírico a uma análise temática de modo a possibilitar interpretação e discussão, para melhor compreender o objeto de estudo. Deste modo, optou-se pela análise de conteúdo temática (Bardin, 1977), que procura dar um significado aos sentidos construídos pelas pessoas participantes, da qual surgiram dimensões de análise emergentes do conjunto de materiais que se foram unificando, através de um processo verdadeiramente exaustivo e implicado, em que foram criadas unidades de significado.

\section{EM TORNO DAS COMPETENCIAS} INTERCULTURAIS DE PROFISSIONAIS: RESULTADOS E DSCUSSÃO

\subsection{AÇÕES FACEAORACISMO ${ }^{10}$, XENOFOBIA ${ }^{11}$, ESTEREÓTIPOS E DISCRIMINAÇÃO}

A permanência e manutenção de uma identidade étnica, construída através de uma etnicidade, é tida como minoritária, no interior de um Estado multiétnico (Bastos \& Bastos, 1999; Casa-Nova, 2005), o que, muitas vezes, acarreta problemas de integração numa sociedade e cultura que atuem de acordo com uma visão etnocêntrica. São várias as vezes em que as minorias étnicas e descendentes de imigrantes se confrontam com atitudes discriminatórias e racistas (Cabecinhas, 2002; Mendes, 2012). Reconhecendo que o trabalho de profissionais com estes/as jovens é diário, há também o confronto com processos de discriminação. Os discursos foram evocando esta questão. Como lidam os/as profissionais com estas atitudes? Que reações/comportamentos/ações têm ao serem confrontados com estes processos?

Os discursos assentaram de forma clara no repúdio face a atitudes discriminatórias:

Eu lido muito mal porque depois... Primeiro, sempre lidei. Depois, se eu sonho que algum dos meus miúdos, e já me aconteceu, eu aí tive que me controlar! Que é chamado de qualquer coisa só porque é preto, ou é discriminado só porque é

\footnotetext{
${ }^{9}$ As "teorias do standpoint" (Harding, 1986) permitem-nos dar conta da vivência das diversidades a partir do lugar em que nos situamos, pelo que o trabalho com as diversidades é encarado de forma diferente nas zonas Norte e Sul do país.

${ }^{10}$ Racismo: "manifesta-se essencialmente pela negação do reconhecimento da singularidade do outro. Na prática, isto significa que os membros das minorias não são tratados como 'indivíduos', mas simplesmente como 'representantes' de uma categoria homogénea" (Cabecinhas, 2007, p. 280).
}

${ }^{11}$ Xenofobia: "do grego xenoi «os estrangeiros» e pfobein «odiar». Literalmente, significa ódio aos estrangeiros" (Echaudemaison, 2001, p. 411). 
preto. (Mediadora Socioeducativa - entrevista)

Um ódio de morte! Incomoda! Incomoda bastante!

(Dinamizador Escolhas 1 - entrevista)

No que diz respeito às ações que colocam em prática quando são confrontados/as com estas situações, o diálogo parece ser a estratégia mais utilizada, como podemos verificar nos seguintes discursos:

Tentando sempre ouvir a pessoa e depois explicar melhor o meu ponto de vista com exemplos, e tenho conseguido mudar algumas mentalidades. (Presidente Associação Juvenil - entrevista)

então uma das nossas estratégias é relativizar ou mesmo dizer "Isso nem faz sentido!", ou dizer "Olha, ótimo! Ainda bem que foste chamado disso. Sabes porquê? Porque estavas lá . . . enriquecer mais a experiência. (Mediadora Socioeducativa entrevista)

Tento-lhes mostrar um bocadinho o estúpido e irracional que isso é. (Coordenadora Projeto Escolhas - entrevista)

O Livro Branco sobre o Diálogo Intercultural, editado pelo Conselho da Europa (2008), declara que a ausência deste diálogo vem contribuindo para os estereótipos que se formam e para o favorecimento da intolerância e da discriminação. Tal como sugerido internacionalmente em políticas de integração, estes/as profissionais optam pelo diálogo para que haja um menor impacto destes fenómenos de discriminação nos/as jovens. Aproximamo-nos aqui de uma competência que, em muitas conversas, foi considerada como essencial no trabalho com jovens descendentes de imigrantes e pertencentes a minorias étnicas: o diálogo, a capacidade de, através da comunicação verbal, fazer entender e compreender os fenómenos, bem como o impacto negativo que determinadas situações discriminatórias podem ter na vida dos/as jovens. Por outro lado, apresentam-se, por vezes, situações em que o "castigo" de grupo parece ser a solução encontrada pelos/as profissionais em situações de discriminação entre os/as jovens.

E: O que é que pensas sobre o racismo?

J1: É uma coisa má!

J2: Eu sou contra o racismo! Não sou racista!

J4: E: Se for uma pessoa de raça negra e nós gozarmos essa pessoa, metem-nos de castigo! (GDF 1)

As atitudes discriminatórias parecem ser reprovadas nos contextos em que estes/as profissionais se inserem, ao mesmo tempo que tentam ser apreendidas de forma positiva e de consciencialização dos/as jovens para uma maior atenção às suas atitudes. Neste âmbito, os/as profissionais demonstram competências ao nível do respeito, tolerância e empatia pelo "outro" diferente, da valorização e compreensão da diversidade cultural, e o entendimento da diferença como uma oportunidade de aprendizagem e não como um obstáculo à mesma (Huber \& Reynolds, 2014; Siewiorek et al., 2013).

\subsection{ESTRATÉGIAS E PRÁTICAS ESPECÍFICAS NA PROMOÇÃO DA INTEGRAÇÃo DOS/AS JOVENS E DE MANUTENÇÃO DA IDENTIDADE}

No que diz respeito à população juvenil na Europa, existem, aproximadamente, 8.3 milhões de jovens nos países da União Europeia que nasceram fora dos países de acolhimento, enquanto o número de descendentes de imigrantes ( $2^{\text {a }}$ geração) está estimado em mais de 4 milhões (Sirius Network, 2014). Estes dados colocam no foco do debate uma clara necessidade de consolidar o trabalho de acolhimento e 
integração de segundas e terceiras gerações de imigrantes (Plano Estratégico para as Migrações, 2015).

Tendo em conta que alguns destes/as jovens possam sentir algumas dificuldades ao nível da integração, que estratégias adotam os/as profissionais para a promoção de uma potencial integração?

Organizamos sempre atividades com jovens de bairros "problemáticos" de modo a integrar todos em vez de criar rivalidades, como lanches culturais e o festival de verão organizado pelo nosso bairro e convidamos jovens de outros bairros problemáticos para atuar juntamente com jovens nossos para os divulgar e também integrar. (Presidente Associação Juvenil - entrevista)

fazer grupos interculturais, que se promova um bocado este diálogo mais... Às vezes é preciso forçar um bocado para a coisa resultar. (Representante Programa Escolhas - GDF 4)

As estratégias que os/as profissionais demonstram promover parecem ser aquelas que, ao mesmo tempo, são promotoras de uma maior manutenção e preservação da identidade étnica e cultural destes/as jovens. A consciência de que uma competência profissional intercultural se constitui através do reconhecimento de que é necessário compreender a diversidade e heterogeneidade internas de todos os grupos culturais (Huber \& Reynolds, 2014) está presente nos discursos e práticas dos/as profissionais. Acreditamos que estas estratégias variem de contexto para contexto; profissionais de diferentes contextos, caracterizados por diferentes tipos de população, parecem colocar em prática diferentes tipos de estratégias contextualizadas. Os/as profissionais parecem reconhecer a variedade e heterogeneidade das culturas presentes nos seus contextos de trabalho e promovem essa integração e compreensão nas suas práticas diárias:

Primeiro, há sempre contactos a nível de religião, não muito nossos, mas tentamos promovê-los com os miúdos... Por exemplo, todos os muçulmanos sabem onde é que são as mesquitas, sabem os horários, tudo isso é sempre muito fácil para eles, estamos sempre muito abertos para os ajudar nesse sentido. (Mediadora Socioeducativa - entrevista)

nós conhecermos essa cultura e termos o cuidado de a tratar como ela é já faz com que não desapareça! Nós aqui tentamos, em relação aos muçulmanos, por exemplo, que é o maior exemplo que temos aqui, tentamos conhecer a cultura deles e trabalhar com eles dentro dos limites que temos nessa cultura. Não vamos tentar incutir-lhes a nossa maneira de pensar, a nossa maneira de fazer as coisas. Eles têm a maneira deles! (Animadora Sociocultural Escolhas - entrevista)

Estas práticas são também promotoras da manutenção da identidade étnica, religiosa e cultural dos/as jovens, ao permitir que tenham acesso e contacto com as dimensões da sua cultura de origem. Alguns exemplos são dados por este profissional do Programa Escolhas:

atividades interculturais, intergeracionais... atividades em que exploramos mesmo os costumes das próprias regiões, dos próprios países, em que fazemos, por exemplo, todos os anos, uma feira gastronómica onde temos várias comidas de vários países, em que pedimos aos pais para confecionarem, por exemplo, um bolo ou uma receita, em que pedimos para eles fazerem uma comida típica do país de forma a que todos provem e que todos saibam. (Dinamizador Escolhas 1 entrevista).

A maior parte das práticas e estratégias referidas são relacionadas com momentos específicos no tempo, e não tanto com estratégias 
integradas, o que pode conduzir a um perigo de "folclorização dos grupos culturais minoritários e o desenvolvimento, face aos mesmos, de atitudes de mera contemplação" (Leite, 2005, p. 6) ou, nas palavras de Stephen Stoer (1999), à prática de um pluralismo cultural benigno que se rege por atos de reconhecimento muito mais do que por atos de conhecimento em que se enfatizam "estilos de vida» relegando para segundo lugar "oportunidades da vida» (elogiase a tolerância em vez de se promover a justiça social) (p. 181). Esta questão é visível no uso, por exemplo, de expressões como a que acima encontramos, de "comida típica", e reforça um conjunto de estereótipos e visões das pessoas e das suas comunidades como circunscritas a formas culturais que reforçam a sua condição de alteridade e de estranheza. As práticas interculturais a que os/as profissionais se referem, como feiras gastronómicas, podem correr $\mathrm{o}$ perigo de se inscreverem neste fenómeno do pluralismo cultural benigno e de folclorização das culturas ao serem práticas momentâneas que ocorrem durante dias e momentos determinados sem que haja uma integração propriamente dita dos aspetos culturais e étnicos dos/as jovens. Do mesmo modo, Sleeter (1991) refere que existe este perigo de, muitas vezes, a educação de membros minoritários da sociedade ganhar a forma de "ajuda benevolente" que vai inibindo o processo de integração e acolhimento no seu estado pleno.

No espaço escolar, a integração de práticas culturais no dia a dia parece estar mais enraizada nas práticas diárias:

não se pretende que eles percam a identidade, obviamente. Até por esse motivo, também introduzimos nos temas que se abordam aqui na escola questões ligadas à cultura deles. (Psicóloga Escolar - entrevista)

nas aulas de Geografia, por exemplo, é uma excelente oportunidade, e eu fiz muitas vezes, aproveitar falar de um certo país para se conhecerem culturas, etnias... Quando se tinha miúdos de outros países na turma, aproveitar essas ocasiões para que eles se dessem a conhecer. (Diretor Agrupamento 2 - entrevista)

A indicação destas práticas parece ultrapassar momentos de mera contemplação das culturas diferentes, aproveitando as práticas correntes e diárias para a valorização e conhecimento de valores culturais distintos. Neste sentido, pensamos que as práticas inter/multiculturais se possam inscrever num ir além de meros momentos em que são "materializadas em danças, cantares e semanas gastronómicas das diversas culturas" (Casa-Nova, 2005, p. 193), inserindo-se, antes, numa "pedagogia contínua e continuada" (Côrte-Real \& Sá, 2014, p. 154), para lá dos "momentos calendarizados".

Este aspeto da necessidade de continuidade das ações no tempo e no espaço torna-se relevante uma vez que "a continuidade das experiências de envolvimento em experiências com elevada qualidade desenvolvimental ligase à possibilidade destas se converterem em importantes acontecimentos transformadores para os sujeitos que nelas participam" (Ferreira, 2006, p. 57). Neste sentido, as práticas inter/ multiculturais só têm qualidade transformadora e integradora da diferença se se assumirem como contínuas no tempo, sendo este/a um/a dos/as principais cuidados e necessidades a longo prazo no trabalho com a diversidade. 
4.3 ESTRATÉGIAS E PRÁTICAS ESPECÍfICAS UTILIZADAS NO TRABALHO COM JOVENS DESCENDENTES DE IMIGRANTES E PERTENCENTES A MINORIAS ÉTNICAS

De forma a melhor compreender quais as competências necessárias e mobilizadas pelos/ as profissionais no trabalho com a diversidade, durante as entrevistas foram abordadas as estratégias específicas que se utilizam no trabalho com os/as jovens. As estratégias mencionadas foram de diversas dimensões e níveis. Aqui, enunciaremos todas as estratégias e, posteriormente, em forma de conclusão e esquematização, apresentaremos as dimensões das estratégias e quais as competências utilizadas e valorizadas.

A compreensão do "outro" e dos seus valores e costumes parecem ser competências valorizadas pelos/as profissionais que entrevistámos:

estar informado das diferentes culturas e costumes, o saber línguas, uma necessidade de sensibilidade. (Profissional Escolhas - GDF 4)

tem de olhar para as suas subjectividades... Claro que nós temos que pesar bem se aquilo vai jogar contra ou a favor de todos, não podemos deixar de falar nessas possibilidades... Olhar para eles sem uma posição de poder. (Investigador FPCEUP GDF 4)

Esta preocupação já era apresentada nos anos 1990 por investigadores/as da área e deve ser chamada e relembrada para esta discussão. Assume-se como crucial a importância da necessidade de o/a professor/a "se dar conta da existência de uma heterogeneidade maior ou menor dos alunos com que trabalha (professor não daltónico)"12 (Cortesão \& Stoer, 1999, p. 24) através do reconhecimento das diferentes diversidades que ganham forma dentro do espaço de sala de aula. A compreensão e respeito pela diferença, bem como uma efetiva e apropriada resposta a essa diferença, a valorização da diversidade cultural e do pluralismo de pontos de vista, a abertura e curiosidade em aprender acerca de novos valores, culturas e costumes (uma "multiperspetiva", habilidade de se descentrar do próprio e tomar o lugar do outro) (Huber \& Reynolds, 2014; UNESCO, 2013) são competências sinalizadas na literatura como indispensáveis no trabalho com a diversidade $\mathrm{e}$ que foram também valorizadas nas palavras de uma Mediadora Socioeducativa:

a visão caleidoscópica ... é aquilo que nós temos que levar para o nosso terreno porque nós ... estamos a ver um fenómeno que tem que ser visto de outras amplitudes e ver isto de outras perspetivas porque a nossa perspetiva é uma, não é? E a dos outros? E a nossa é que está correta? Não tem que ver... tem que ver com a que for mais completa, e nós atingimos essa plenitude por aí. (Mediadora Socioeducativa - entrevista)

A valorização da língua materna parece ser também uma das competências essenciais neste trabalho, uma vez que permite a manutenção da identidade regional dos/as jovens:

valorização das línguas maternas para além da promoção da língua portuguesa. (Representante ACM - entrevista)

Neste sentido, urge a necessidade de se entender a influência da linguagem e o desenvolvimento de uma "communicative awareness" (Huber \& Reynolds, 2014, p. 21), bem como o entendimento de que não existe uma forma única de expressão, mas sim uma multiplicidade de formas verbais e não-verbais

\footnotetext{
${ }^{12}$ Este conceito surge em contraponto ao de "professor daltónico", que "não será sensível à heterogeneidade, ao 'arco-íris' que tem nas mãos” (Stoer \& Cortesão, 1999, p. 20).
} 
que diferentes culturas podem adquirir.

Para uma prática educativa inter/multicultural, os/as profissionais referiram também a necessidade de se criar uma relação de proximidade com estes/as jovens:

Eu acho que é a proximidade com eles. Ninguém aqui é mais que ninguém, ninguém aqui é menos que ninguém. Somos todos iguais, temos que nos respeitar. (Coordenadora Projeto Escolhas entrevista)

Estas ideias levam-nos para a questão de a prática profissional também se poder inscrever numa prática de relação com o Outro, com maior ênfase nos contextos de multiculturalidade em que há a consciência de que "[a] interculturalidade vive-se, pratica-se e aprende-se na relação com os outros, a partir de uma cultura de trabalho em colaboração e parceria" (Farmhouse, 2011, p. 5), bem como de uma necessidade de se estabelecer uma relação de empatia capaz de corresponder aos pensamentos, crenças, valores e sentimentos de outras pessoas (Huber \& Reynolds, 2014). Este ideal de cultura de partilha e da vivência da interculturalidade como uma experiência de aprendizagem mútua está presente em alguns discursos:

ideia de aprendizagem mútua, de um espaço que me permite crescer, daquilo que são as minhas competências, digamos, à partida, inatas, mas também daquilo que são as oportunidades que, naturalmente, teria direito a ter. (Membro Associação Juvenil - GDF 4)

Eu estou aqui para os ajudar, da mesma maneira que eles estão para me ajudar a mim também, se eu precisar. (Coordenadora Programa Escolhas entrevista)
Os/as profissionais em contextos de diversidade parecem desenvolver um "permanente exercício de uma atitude crítica, para o interesse de confrontar perspectivas antagónicas" (Stoer \& Cortesão, 1999, p. 31). O conceito de professor reflexivo proposto, entre outros, por Stoer e Cortesão (1999) adequa-se à variedade de profissionais em contextos educativos, tendo em conta a necessidade da existência de um/a "profissional reflexivo" que "age de certo modo como investigador no seu terreno de acção e que através destas preocupações e actuações se vai enriquecendo interiormente, se vai construindo, num verdadeiro processo de formação" (Stoer \& Cortesão, 1999, p. 34).

A adequação de práticas surgiu também como uma competência essencial a ser desenvolvida, bem comoum trabalhosensívelà individualidade, como nos foi dito por profissionais do Programa Escolhas e uma Representante da Rede Sirius:

É ter atenção individual em cada um deles. (Animadora Sociocultural Escolhas - entrevista)

Se trabalharmos como se fôssemos um clube inglês, nós vamos juntá-los na sua gavetinha e vamos trabalhar as especificidades que cada grupo tem, se estivermos no bazar do Kuwait são as diversidades todas misturadas e vamos ter que arranjar tendas que acolham as diferentes diversidades. (Representante Rede Sirius/NAOS GDF 4)

Pensar em mudar uma refeição, por exemplo, estarmos todos uma semana fora e ter que alterar de forma a que não existisse carnes de porco na refeição porque um jovem muçulmano não pode comer... E, lá está, o não lanchar em frente na altura do Ramadão. (Dinamizador Escolhas 1 entrevista) 
A necessidade de adequação de práticas é sinalizada no que se refere à prática educacional de docentes em que se espera que definam e conceptualizem a educação de acordo com os seus objetivos e práticas e com os grupos sociais com que lidam (Sleeter, 1991), bem como nos discursos políticos onde se elenca a necessidade de "the methods used have to be designed to fit the individuals in the group, they have to be various and inclusive" (Organizing Bureau of European School Student Unions [OBESSU], 2014 , p. 3). Assim, as práticas educativas devem ser adequadas, e aqui acreditamos que o possam ser não só a jovens com background imigrante, mas à variedade existente dentro do espetro da juventude, conforme as necessidades e idiossincrasias de cada indivíduo.

4.4 TIPO DE PREPARAÇÃO, AO NíVEL DA FORMAÇÃO INICIAL, PARA O TRABALHO COM AS DIVERSIDADES

Aquando da realização das entrevistas com os/as profissionais, estes foram questionados/ as acerca da preparação que tiveram, ao nível da sua formação inicial, para lidar com as diversidades. Apesar de encontrarmos áreas de formação distintas, as respostas foram bastante coincidentes nos/as diferentes profissionais:

não tive nenhuma área específica para tratar disso. . . Não tive formação nenhuma de base, formação inicial, com minorias. (Diretor Agrupamento 1 entrevista)

Não tive! (Dinamizadora Programa Escolhas entrevista)

Eu tive um professor de Psicoterapia que uma vez levou um caso prático de uma escola americana qualquer em que se falava da interculturalidade. Nunca mais falei desse assunto e acho que é um assunto que se fala muito pouco! Não dão o verdadeiro peso à necessidade de saber lidar com outras culturas. (Coordenadora Projeto Escolhas entrevista)

Não! Tive só apenas a licenciatura em Psicologia, o mestrado que está mesmo a acabar, mas nenhuma em específico para lidar com isso! (Animadora Sociocultural Escolhas - entrevista)

$\mathrm{Na}$ minha formação inicial, na licenciatura de Psicologia, não. (Psicóloga Escolar - entrevista)

na minha formação inicial, como professor de Geografia, não! Claro que as outras culturas iam sendo abordadas por causa do estudo dos países, mas especificamente para trabalhar com a diversidade não! (Diretor Agrupamento 2 - entrevista)

Através destes discursos compreende-se que a questão do trabalho com as diversidades, ao nível da formação inicial, mesmo na formação de profissionais da área do trabalho social, não está contemplada nos currículos e, quando é abordada, é sempre de uma forma residual. De facto, alacuna na formação inicial de profissionais e professores/as tem sido largamente estudada e analisada, havendo a ideia de que "as instituições de ensino superior encarregadas da formação inicial dos professores... deveriam, por sua vez, introduzir nos seus curricula... espaços de reflexão e de transmissão de conhecimento exigidos por esta nova escola multicolor" (Miranda, 2004, p. 33).

Dados recolhidos no âmbito do Projeto NAOS acerca do modo como as questões da diversidade étnica e cultural estão a ser tratadas nos currículos de formação inicial de professores/as em Portugal levam a concluir que a maior parte das instituições de formação abordam as questões da interculturalidade de forma muito residual, sendo que a maior parte das unidades curriculares que incluem estas preocupações são de cariz optativo. $\mathrm{Na}$ verdade, "muito poucos países definiram um conjunto 
de competências comuns diretamente ligadas à cidadania que deveriam ser adquiridas por todos os professores recém-formados" (Rede Eurydice, 2012, p. 15), o que, como vemos através da literatura e dos dados empíricos deste estudo, se demonstra também no contexto português. Esta é uma preocupação que tem sido considerada na análise da formação inicial de docentes mas que pode ser alargada à formação de outros/as profissionais da área da educação e do trabalho social, como os resultados deste estudo vêm provar, uma vez que serão confrontados/as com múltiplas realidades contextuais. Assim, surge a necessidade de "training in the topics of migration, acculturation, social psychology phenomena, language (including second language learning, formative assessment, language diagnostics and intercultural education), diversity and ethnic identity issues relating to the diverse and challenging environments" (Sirius Network, 2014, p. 9).

As lacunas ao nível da formação inicial de profissionais da área social e de professores/ as são sentidas pelos sujeitos que participaram neste estudo:

Agora, o que é dramático é, num período em que todas estas questões se põem, realmente não haver praticamente nada de trabalho neste campo! Não se faz nada ou quase nada! (Professora Universitária - entrevista)

mesmo dentro da área social, que era uma área que, à partida, se esperaria que os nossos cursos superiores nos preparassem para essa diversidade... Aquele estudo que eu fiz sobre as representações sociais da pobreza, os técnicos que eu entrevistei dizem-nos, maioritariamente, que $o$ curso não os preparou para a diversidade nem para a multiculturalidade nem para... Portanto, focam muito essa questão, mesmo os cursos da área social, sociologia, serviço social, psicologia, tudo mesmo... Todos os cursos abordam mas de uma forma demasiado superficial, preocupados só se, quando estamos a passar um inquérito, as pessoas autorizam ou não e fica escrito, para salvaguardar tudo o que a gente venha a dizer a partir dali, mas isso não é só, a ética é muito mais. (Representante Rede Europeia Anti-Pobreza - GDF 4)

Estas lacunas têm um impacto ao nível da prática profissional, pois "significa que nós estamos a formar profissionais, professores e professoras, que não têm no seu currículo, na formação inicial, que não têm estas questões das diversidades, do multilinguismo, etc." (Representante Rede Sirius/NAOS - GDF 4). Esta ideia corrobora estudos anteriores (Pereira, 2009a, 2009b, 2010; Pereira, Carolino, \& Lopes, 2007) que têm enfatizado que os/as docentes consideram a sua formação inicial inapropriada para encarar os problemas e dilemas que a escola atravessa nos dias de hoje.

Existe também a preocupação em colmatar as necessidades sentidas ao nível desta lacuna na formação inicial de profissionais:

estamos a reformular a nossa oferta a nível de formação contínua para tentarmos corresponder exatamente a essa necessidade. Foi uma das coisas que os nossos alunos, nos inquéritos, procuraram dizer foi que achavam que faltava formação nessa área. (Docente ESE - entrevista)

Apesar de existir uma lacuna ao nível da formação inicial no que ao trabalho com as diversidades diz respeito, algumas instituições parecem mobilizar esforços para que este seja um trabalho mais desenvolvido na formação inicial de professores/as e outros/as profissionais.

\subsection{PRÁtica PROFISSIONAL COMO ELEMENTO DE FORMAÇÃO}

Havendo a consciência, por parte dos/as profissionais, de que a sua formação inicial não 
os/as preparou para o trabalho com a diversidade cultural e étnica, estes/as parecem encontrar na prática profissional e nas experiências do trabalho diário uma importante ferramenta de formação. Os/as diferentes profissionais fizeram referência à prática profissional como uma importante forma de aprendizagem:

a prática acabou por me formar nesse sentido. (Mediadora Socioeducativa - entrevista)

só no contacto mesmo com a diferença é que vai fazer com que nós consigamos trabalhar nesse sentido. (Investigador FPCEUP - GDF 4)

Vai-se aprendendo ao longo do tempo. (Dinamizador Escolhas 1 - entrevista)

Foi mesmo, com o ver do tempo, daquilo que eu vivi até agora, com a experiência que tenho tido no bairro, que que me habituei. (Dinamizadora Escolhas - entrevista)

o próprio contacto com a realidade vai sendo importante para percebermos como lidar com determinadas situações. (Diretor Agrupamento 2 - entrevista)

A "prática pedagógica parece ser... uma das componentes mais valorizadas na sua formação" (Galveias, 2008, p. 7), tendo sido referida por praticamente todos/as os/as profissionais. Não colocando de parte a necessidade de uma formação mais cuidada e atenta às problemáticas da diversidade, os/as profissionais parecem atribuir à prática profissional uma maior valorização, pois acreditam que é no contacto com a realidade e as comunidades que as suas competências vão sendo desenvolvidas.

Não havendo muita oferta formativa neste âmbito, os/as profissionais parecem ser autodidatas no seu próprio processo de formação e aprendizagem e parecem desenvolver estratégias por forma a enriquecer a sua prática profissional e de contacto com jovens descendentes de imigrantes e pertencentes a minorias étnicas, como fica explícito no discurso da coordenadora de um dos Projetos Escolhas:

Tive que ir aprendendo um bocadinho por mim... tive que andar à procura, a ler coisas fora do país, principalmente... eram experiências que eu fazia, ia falando com as pessoas, pedia-lhes para me ajudarem a compreender a cultura delas e mostrava abertura para aprender a cultura delas e para explicar melhor a minha, também, mas se calhar no meio eu fiz muitas asneiras... De algumas estou consciente, de outras se calhar não consegui ser consciente e fiz muitas asneiras... (Coordenadora Projeto Escolhas - entrevista)

Aqui, mais uma vez, impõe-se a necessidade da construção de uma profissionalidade reflexiva, que permite o desenvolvimento de uma prática profissional crítica e atenta e a relação entre a teoria e a prática (Bolton, 2014). Os/as profissionais destes contextos parecem colocar em prática competências reflexivas, ou seja, encontram "strategies to question [their] own attitudes..., values, assumptions, prejudices and habitual actions" (Lowlands, 2014, p. 7).

Em forma de resumo, apresentamos a imagem seguinte (Figura 1), onde é possível verificar as dimensões e competências específicas observadas na exploração deste estudo: 


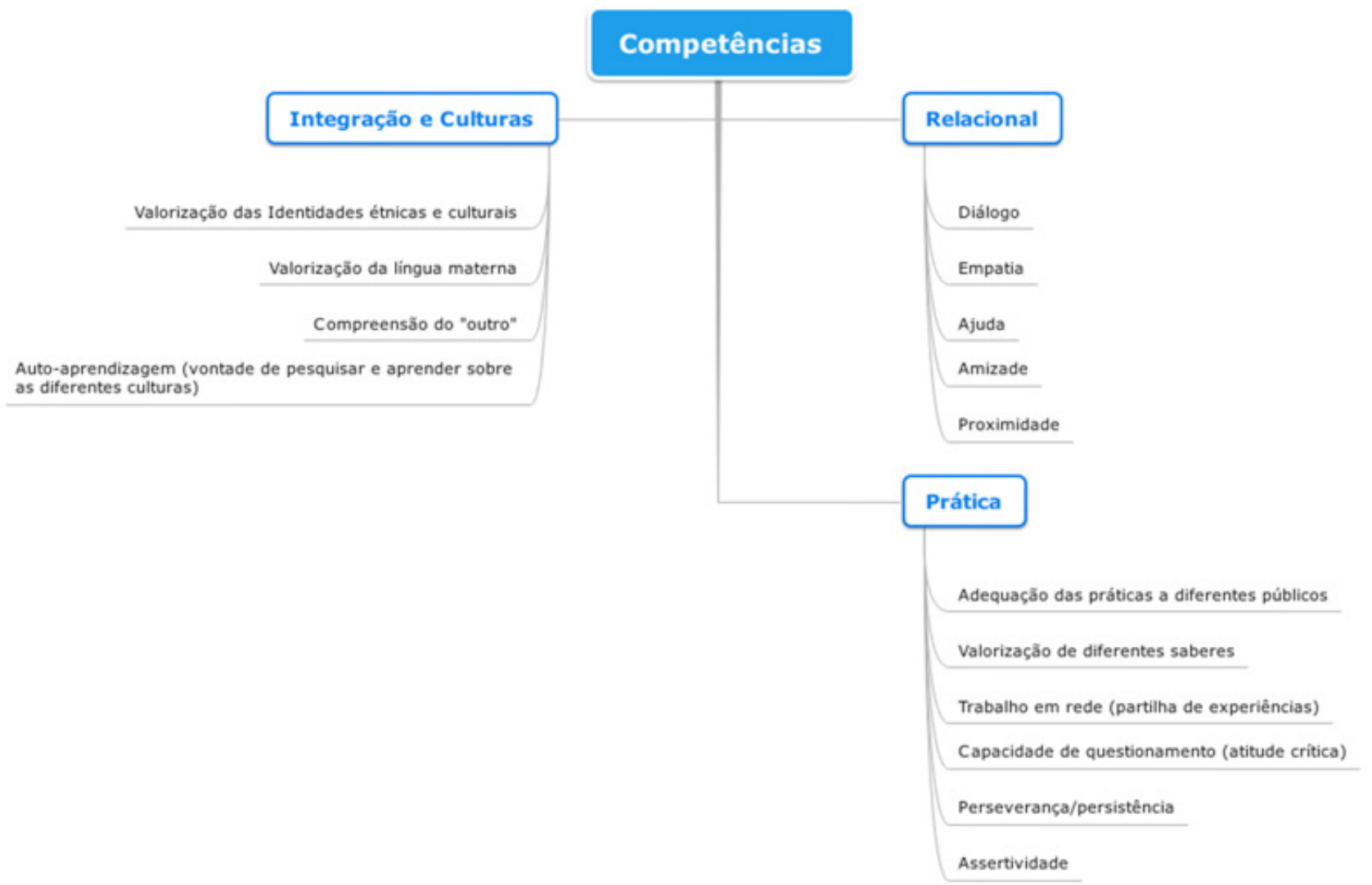

F I G U RA 1 - Esquema-resumo dos resultados

\section{CONSIDERAÇÕES FINAIS}

A necessidade da construção de uma profissionalidade atenta à multiplicidade de vozes presentes nos contextos educativos é a ideia-chave retirada desta investigação. Esta parece ser uma ideia que se mantém e que não deixa de ser necessário discutir e analisar à luz das preocupações com a diversidade cultural, contribuindo para um trabalho enriquecedor com a diferença étnica e cultural. A construção de saberes e o desenvolvimento de competências voltados para estas necessidades é também essencial. Esta construção de competências não poderá ser

\footnotetext{
limited to the celebration of difference, but rather are able to build the pedagogical devices and the social and institutional conditions that are necessary for each particular situation, so that children and
}

young people, regardless of their social and cultural background or subjective condition, may benefit from ... education. (Pereira, 2013, p. 489)

Tendo em conta os contributos teóricos e empíricos deste estudo, as dimensões de competências consideradas relevantes no trabalho desenvolvido com jovens descendentes de imigrantes e pertencentes a minorias étnicas foram as seguintes: uma dimensão relacional (relação e proximidade com os/as jovens); uma dimensão prática (onde são referidas as competências práticas no trabalho com a diversidade); e uma dimensão de integração cultural e social (relacionada com competências específicas associadas às identidades étnicas e culturais).

A abordagem das competências neste trabalho não se prendeu com o objetivo de encontrar soluções indiscutíveis para os/as profissionais em contextos educativos, pois acreditamos que 
estes/as articulam, diariamente, um leque de estratégias e competências fundamentais para o trabalho com diferentes comunidades - o que nos permite, também, pensar na questão de que todo/a e qualquer profissional se assume como um/a profissional da diversidade, quer estes/as profissionais sejam docentes ou outros/as agentes que se encontrem presentes nos diferentes contextos, pois articulam, diariamente, relações e práticas em que as questões da diferença e diversidade são iminentemente integradas.

Pretendeu-se, pois, contribuir para a discussão em torno da prática profissional e do pensamento acerca das estratégias específicas que podem ser auxiliadoras de uma integração positiva de jovens descendentes de imigrantes e pertencentes a minorias étnicas. Assim, podemos concluir que as competências mais valorizadas e colocadas em prática são aquelas que vão ao encontro do respeito pelo Outro e da consciência de que "The human heterogeneity and the cultural complexity that characterize today's educational contexts require a mastery of professional knowledge and skills" (Pereira, 2013, p. 478). É, por isto, evidente a importância de professores/as e demais atores educativos (Paes \& Vitorino, 2011) no desenvolvimento de estratégias e práticas promotoras de uma maior justiça social capaz de desconstruir estereótipos e de diminuir o impacto das desigualdades.

Tendo em conta que, no contexto português, a diversidade étnica representa apenas uma pequena parcela da diversidade cultural, o contributo deste estudo permite também pensar nas questões que rodeiam a diversidade relacionada com as classes sociais, a orientação sexual, etc., que trazem para os contextos educativos uma série de conflitos. Sabe-se que "os conflitos são essenciais na construção de relações mais justas, possibilitando a reafirmação da lei e dos valores vigentes num determinado espaço-tempo" (Neves \& Malafaia, 2012, p. 64). No entanto, sem uma abordagem positiva e uma perspetiva de resolução de conflitos que aborde o conflito de forma a que este seja um ganho/ aprendizagem para os envolvidos, o conflito não deixará de ser encarado como algo negativo. O papel dos/as docentes e demais profissionais é aqui crucial, na medida em que atuam como mediadores nos seus contextos. A mediação surge como "meio alternativo de resolução de conflitos através do qual as partes em conflito, apoiadas por um terceiro elemento imparcial e tendencialmente neutro, procuram a solução para o seu diferendo de forma satisfatória para ambas as partes" (Freire, 2010, p. 65).

Nesta perspetiva, propõe-se uma visão de Educação para a Resolução de Conflitos (Morgado \& Oliveira, 2009) que constitui um movimento de educação para a paz, que requer a promoção das diferentes criações culturais dos indivíduos e dos povos. É com este fim que a educação para a paz visa desenvolver competências de comunicação, de construção do consenso e de sensibilidade, sendo que se enquadra numa perspetiva multi e intercultural, não preconceituosa. Cabe aos agentes educativos esta função, de trazer para a escola soluções que abarquem e abranjam os contextos e possibilidades destes/as jovens, contribuindo para o "desenvolvimento de competências pessoais, como a escuta activa, o diálogo, a auto-regulação e autocontrolo, a empatia e a responsabilização" (Freire, 2010, p. 67). A introdução, por exemplo, em meios escolares da figura do mediador da comunidade, alguém externo à escola mas que traz contributos essenciais para a mediação por ter uma aproximação aos valores étnicos e linguísticos dos/as estudantes, pode ser colmatada com uma maior heterogeneidade do corpo docente, que pode, potencialmente, traduzir-se como a melhor forma de mediação cultural. Esta mudança deve ser cuidada, de forma a que este processo não se torne potenciador das diferenças culturais e se crie uma espécie de gueto cultural. Pretendemos que a educação seja, no fundo, uma educação 
para o empoderamento (Sleeter, 1991), capaz de abarcar as diferenças de cada um/a ao mesmo tempo que as integra numa perspetiva ampla e de compreensão.

O papel dos contextos educativos e dos profissionais, no seu trabalho com jovens descendentes de imigrantes e pertencentes a minorias étnicas, assume uma função social e de aprendizagem significativas para os/as jovens e permite a "coexistência de diferentes grupos nacionais, culturais ou étnicos no mesmo espaço" (Jardim, 2014, p. 88). No fundo, estes/ as profissionais e contextos parecem "contribuir para uma construção, eventualmente conflitual, negociada, de uma comunidade de comunidades culturais que se reconhecem, se respeitam e interagem" (Cortesão \& Stoer, 1995, p. 42) através da valorização de múltiplas experiências e saberes.

\section{REFERÊNCIAS}

Araujo, V. (2009). A multiculturalidade nas políticaseducacionaise a formação deprofessores: Brasil e Portugal (Tese de doutoramento). Universidade Federal de São Carlos, São Paulo, Brasil.

Banks, J. A. (1995). Multicultural education: Historical development, dimensions, and practice. In J. A. Banks (Ed.), Handbook of research on multicultural education (pp. 3-49). New York: MacMillan.

Bardin, L. (1977). Análise de conteúdo. Lisboa: Edições 70.

Bastos, J., \& Bastos, S. (1999). Portugal multicultural. Lisboa: Fim de Século Edições.

Bernstein, B. (1990). Poder, educación y conciencia. Sociología de la transmisión cultural. Barcelona: Ed. El Roure.

Bogdan, R., \& Biklen, S. (1994). Investigação qualitativa em educação: Uma introdução à teoria e aos métodos. Porto: Porto Editora.

Bolton, G. (Ed.) (2014). Reflective practice: Writing and professional development. London:
Sage Publications.

Cabecinhas, R. (2002). Racismo e etnicidade em Portugal: Uma análise psicossociológica da homogeneização das minorias (Tese de doutoramento). Universidade do Minho, Braga, Portugal.

Cabecinhas, R. (2007). Preto e branco: A naturalização da discriminação racial. Porto: Campo das Letras.

Casa-Nova, M. J. (2005). (I)Migrantes, diversidades e desigualdades no sistema educativo português: Balanço e perspectivas. Ensaio: Avaliação e Políticas Públicas em Educação, 13(47), 181-216.

Casa-Nova, M. J. (2006). A relação dos ciganos com a escola pública: Contributos para a compreensão sociológica de um problema complexo e multidimensional. Interacções, 2, 155-182.

Conselho da Europa. (2008). Livro branco sobre o diálogo intercultural "Viver juntos em igual dignidade". Estrasburgo: Conselho da Europa.

Côrte-Real, M., \& Sá, M. H. A. (2014). Diálogo intercultural na escola portuguesa precisa-se!. Educação, Sociedade \& Culturas, 41, 149-170.

Cortesão, L., \& Stoer, S. (1995). Projectos, percursos, sinergias no campo da educação inter/multicultural: Relatório final. Porto: FPCEUP-CIIE.

Cortesão, L., \& Stoer, S. (1999). A interculturalidade e a educação escolar: Dispositivos pedagógicos e a construção da ponte entre culturas. Inovação: Revista do Instituto de Inovação Educacional [Separata], 9, 35-51.

Cortesão, L., Costa, A. S., Rodrigues, L., \& Trindade, R. (2002). Mergulhando no arco-íris sócio-cultural: Contributo para o conhecimento dos trabalhos sobre educação e diversidade em Portugal. Investigar em Educação, 1,19-99.

Council of Europe. (2009). Diversity and inclusion: Challenges for teacher education. Strasbourg: Directorate general IV Directorate of Education and Languages, Unit 
of European Education Policies.

Echaudemaison, D. (2001). Dicionário de Economia e Ciências Sociais. Porto: Porto Editora.

Farmhouse, R. (2011). Nota de abertura. In I. Paes \& T. Vitorino (Coords.), Comunidades educativas comprometidas com a diversidade. Propostas e reflexões a partir de práticas de formação-ação (pp. 5-7). Lisboa: Alto Comissariado para a Imigração e Diálogo Intercultural.

Ferreira, P. (2006). Concepções de cidadania e experiências de participação na sociedade civil: Uma perspectiva do desenvolvimento psicológico (Tese de doutoramento). Faculdade de Psicologia e de Ciências da Educação da Universidade do Porto, Porto, Portugal.

Freire, I. (2010). A mediação em educação em Portugal. In J. A. Correia \& A. M. C. Silva (Orgs.), Mediação: (D)Os contextos e (d)os actores (pp. 59-70). Porto: Afrontamento.

Galveias, M. F. (2008). Prática pedagógica: Cenário de formação profissional. Interacções, 8, 6-17.

Hall, S. (2003). “Que 'negro' é esse na cultura negra?”. In S. Hall (Ed.), Da diáspora: Identidades e mediações culturais (pp. 335349). Belo Horizonte: Editora UFMG.

Harding, S. (1986). The science question in feminism. Ithaca: Cornell University Press.

Huber, J., \& Reynolds, C. (2014). Developing intercultural competence through education. Brussels: Council of Europe.

Jardim, C. (2014). Vindos da Europa... Sentidos e compromissos de uma experiência de serviço voluntário europeu (Dissertação de mestrado). Faculdade de Psicologia e de Ciências da Educação da Universidade do Porto, Porto, Portugal.

Leite, C. (2003). Para uma escola curricularmente inteligente. Porto: Edições ASA.

Leite, C. (2005, setembro). O currículo escolar e o exercício docente perante a multiculturalidade - Implicações para a formação de professores. In Centro Paulo Freire (Org.), Paulo Freire:
Desafios à sociedade multicultural - Actas do V colóquio Internacional Paulo Freire (pp. 1-16). Recife, Brasil. Disponível em: https://sigarra. up.pt/flup/pt/pub_geral.pub_view?pi_pub_ base_id $=14381$

Lowlands, D. (2014). Reflective practice: An introduction. In G. Bolton (Ed.), Reflective practice: Writing and professional development (pp. 1-16). London: Sage Publications.

Magalhães, A., \& Stoer, S. (2005). "A diferença somos nós": A gestão da mudança social e as políticas educativas e sociais. Porto: Edições Afrontamento.

Magalhães, A., \& Stoer, S. (2011). Pensar as diferenças: Contributos para a educação inclusiva. In D. Rodrigues (Org.), Educação inclusiva: Dos conceitos às práticas de formação (pp. 29-43). Lisboa: Horizontes Pedagógicos.

Mendes, M. M. (2012). Identidades, racismo $e$ discriminação: Ciganos da AML. Lisboa: Caleidoscópio.

Mendes, M., Magano, O., \& Candeias, P. (2014). Estudo nacional sobre as comunidades ciganas. Observatório das comunidades ciganas. Lisboa: Alto Comissariado para as Migrações.

Miranda, F. (2004). Educação intercultural e formação de professores. Porto: Porto Editora.

Morgado, C., \& Oliveira, I. (2009). Mediação em contexto escolar: Transformar o conflito em oportunidade. Exedra, 1, 43-56.

Nata, G. (2007). Diferença cultural e democracia: Identidade, cidadania e tolerância na relação entre maioria e minorias (Tese de doutoramento). Faculdade de Psicologia e de Ciências da Educação da Universidade do Porto, Porto, Portugal.

Neves, T., \& Malafaia, C. (2012). Gestão de conflitos: Uma experiência, um guia. Porto: Legis Editora.

OECD Report (2010). Educating teachers for diversity: Meeting the challenge. Paris: OECD.

Organizing Bureau of European School Student Unions. (2014). Guidelines on social inclusion in education. Disponível em: https://www.obessu. org/site/assets/files/1310/2014_-_guidelines_ 
on_social_inclusion_in_education.pdf

Paes, I., \& Vitorino, T. (Coord.). (2011).

Comunidades educativas comprometidas com a diversidade. Propostas e reflexões a partir de práticas de formação-ação. Lisboa: Alto Comissariado para a Imigração e Diálogo Intercultural.

Pereira, A. (2004). Educação multicultural: Teorias e práticas. Porto: Edições ASA.

Pereira, F. (2009a). Conceptions and knowledge about childhood in initial teacher training: Changes in recent decades and their impact on teacher professionality and on schooling in childhood. Teaching and Teacher Education, 25(8), 1009-1017.

Pereira, F. (2009b). Governo da infância e profissionalidade docente: Narrativas em formação inicial de professores. Educação, Sociedade \& Culturas, 29, 89-108.

Pereira, F. (2010). Infância, educação escolar e profissionalidade docente: Um mapeamento social dos discursos em formação inicial de professores. Lisboa: Fundação Calouste Gulbenkian e Fundação para a Ciência e a Tecnologia.

Pereira, F. (2013). Concepts, policies and practices of teacher education: An analysis of studies on teacher education in Portugal. Journal of Education for Teaching, 39(5), 474491.

Pereira, F., Carolino, A., \& Lopes, A. (2007). A formação inicial de professores do $1^{\circ} \mathrm{CEB}$ nas últimas três décadas do séc. XX: Transformações curriculares, conceptualização educativa e profissionalização docente. Revista Portuguesa de Educação, 20(1), 191-219.

Perrenoud, P., Paquay, L., Altet, M., \& Charlier, É. (2001). Formando professores profissionais. Quais estratégias? Quais competências?. Porto Alegre: Artmed Editora.

Plano Estratégico para as Migrações. (2015). Resolução do Conselho de Ministros N. ${ }^{\circ}$ 12-B/2015, 20 de março de 2015. Disponível em: https://www.acm.gov.
pt/documents/10181/222357/PEM_net. pdf/3a515909-7e66-41e8-8179-e3aa5e0c7195

Rede Eurydice. (2012). A educação para a cidadania. Lisboa: Direção-Geral de Estatísticas da Educação e Ciência. Retirado em março 16, 2016, de http://eacea.ec.europa. eu/education/eurydice

Severiens, S., Wolff, R., \& van Herpen, S. (2013). Teaching for diversity: A literature overview and an analysis of the curriculum of a teacher training college. European Journal of Teacher Education, 37(3), 295-311.

Siewiorek, A., Vivitsou, M., \& von Reis Saari, J. (2013). Key competences in practice. KeyCoNet 2013 literature review: Key competence development in school education in Europe. Project: KeYCoNet: Key Competence Network on School Education. Disponível em: http://keyconet.eun.org/c/document_library/ get_file?uuid=060f39a 1-bd86-4941-a6ca8b2a3ba8548e\&groupId $=11028$

Silva, D. (2016). O trabalho educativo com jovens descendentes de imigrantes e de minorias étnicas: Competências profissionais, estratégias $e$ políticas de capacitação (Dissertação de mestrado). Faculdade de Psicologia e de Ciências da Educação da Universidade do Porto, Porto, Portugal.

Silva, S. M. (2008). Figuras e configurações da estranheza: $\mathrm{O}$ mundo da vida e o mundo da escola. E-cadernos CES, 1, 141-159.

Silva, S. M. (2011). Da casa da juventude aos confins do mundo. Etnografia de fragilidades, medos e estratégias juvenis. Porto: Edições Afrontamento.

Sirius Network. (2014). A clear agenda for migrant education in Europe. Brussels: Sirius Network.

Sleeter, C. (1991). Multicultural education and empowerment. In C. Sleeter (Ed.), Empowerment through multicultural education (pp. 1-26). New York: Suny.

Stoer, S. (1994). Construindo a escola democrática através do "campo da recontextualização pedagógica”. Educação, Sociedade \& Culturas, 


\section{$1,7-27$.}

Stoer, S. (1999). Combatendo a educação multicultural benigna. In Universidade de Lisboa (Org.), Actas do Encontro "Um olhar sobre o outro" (pp. 177-183). Lisboa: Departamento de Ensino Básico.

Stoer, S., \& Cortesão, L. (1999). "Levantando a pedra": Da pedagogia inter/multicultural às políticas educativas numa época de transnacionalização. $\quad$ Porto: Edições Afrontamento.

Tavares, C., \& Sanches, I. (2013). Gerir a diversidade: Contributos da aprendizagem cooperativa para a construção de salas de aula inclusivas. Revista Portuguesa de Educação, 26(1), 307-347.

UNESCO. (2006). Guidelines on intercultural education. Paris: UNESCO.

UNESCO. (2013). Intercultural competences. Paris: Intersectoral Platform for a Culture of Peace and Non-Violence, Bureau for Strategic Planning.

Zimenkova, T. (2011). DIVERSITY: Future project or current challenge? Construction of the term diversity within citizenship education in Europe. Educação, Sociedade \& Culturas, $32,23-40$.

KNOWING CONTEXTS, KNOWING PROFESTIONALS: A CONTRIBUTION TO EXPLORE THE DEVELOPMENT OF INTERCULTURAL COMPETENCES IN EDUCATIONAL CONTEXTS

\section{Abstract}

The increasing mobility and migration movements in the European contemporary society have impacted multiple social contexts, bringing particular challenges to the education field. In this line, cultural diversity issues become heard, not only due to the emergence of mediatic situations, but also because they remind us of "old" diversities, sometimes forgotten. This article aims to contribute to a discussion which combines global concerns and influences local education contexts. This contribution comes from a qualitative study that aimed to account for competences that were valued, appropriated and used by professionals in formal, non-formal and informal education contexts, while working with ethnic diversities, namely with young people with a migrant background and from ethnic minorities. The semi structured interviews and the focus group discussions allowed us to know a set of professional competences which are organized into three dimensions: relational, practical and cultural and social integration.

KEY-WORDS: Inter/multicultural education; Professional competences; Cultural diversity

\begin{tabular}{lllr}
\multicolumn{1}{c}{ CONNAîTRE LES } & \multicolumn{2}{c}{ CONTEXTES, } \\
CONNAITTRE LES & \multicolumn{1}{c}{ PROFESIONNELS } \\
CONTRIBUTION & À & EXPLORER & LE \\
DÉVELOPPEMENT & DES & COMPÉTENCES \\
INTERCULTURELLES & DANS r DES \\
CONTEXTES ÉDUCATIFS &
\end{tabular}

\section{RESUMÉ}

Laugmentation des mobilités et des mouvements migratoires dans la société européenne contemporaine répercute dans les plusieurs contextes sociaux, en entrainant des nouveaux défis pour le champ éducatif, particulièrement. Les questions de la diversité culturelle deviennent audibles même par l'émergence d'aspects médiatisés, mais aussi parce qu'elles nous rappellent les "vieilles" diversités, parfois oubliées. Cet article cherche à contribuer pour une discussion qui combine les préoccupations globales qui s'allongent à des contextes éducatifs locaux, où les diversités culturelles sont vécus et se produisent en impliquant des différentes figures. Cette contribution advient d'une recherche qualitative qui cherche à démontrer des compétences valorisées, appropriées et 
mobilisées par plusieurs professionnels en contextes éducatifs formels, informels et nonformels dans leurs travails avec la diversité ethnique, plus spécifiquement avec des jeunes descendants d'immigrants et de minorités ethniques. Les entretiens semi-directifs et les groupes de discussions ont permis une lecture d'un ensemble de compétences professionnels organisées en trois dimensions : une dimension relationnelle, une dimension pratique et une dimension d'intégration culturelle et sociale.

MotS-CLÉ: Education inter/multiculturelle ; Compétences professionnelles ; Diversité culturelle

\footnotetext{
${ }^{\text {I }}$ Programa Doutoral em Ciências da Educação \& Centro de Investigação e Intervenção Educativas, Faculdade de Psicologia e de Ciências da Educação, Universidade do Porto, Portugal. ORCID: 0000-0002-4560-177X

${ }^{\text {I }}$ Centro de Investigação e Intervenção Educativas, Faculdade de Psicologia e de Ciências da Educação, Universidade do Porto, Portugal. ORCID: 0000-0002-2688-1171
} 